In Canada, the story of LSD's regulation is particularly revealing. The issue first arose in 1962 amid the thalidomide scandal. As regulators discussed the appropriate schedule for thalidomide, they paused to consider whether LSD should be placed under similar restrictions. The medical community at that moment banded together to defend the prerogative of clinicians to set the criteria for determining the efficacy of a drug. A few years later, under pressure from the Senate led by Senator Hartland Molson of the Molson Brewery family, physicians yielded to the recommendations of policymakers. ${ }^{4}$ Suffice to say, the leading therapeutic application was using LSD to treat alcoholism, and Senator Molson pushed the law forward, while the brewing industry enjoyed regulations that helped bring beer to market.

The bureaucracy of drug regulation has grown exponentially over the past half century and has recently come under criticism for making political rather than evidence-based decisions. In 2007, British pharmacologist David Nutt published a harm-ranking scale in The Lancet, where he argued that psychedelic drugs were much less harmful than the regulated substances of nicotine and alcohol. ${ }^{5} \mathrm{He}$ was later fired from his position on the Advisory Council on the Misuse of Drugs, which catapulted him into the debates over renewing medical research on psychedelics. He subsequently pointed to the gulf that has grown between clinical drug trials and government regulations, lamenting the "daunting bureaucratic labyrinth that can dissuade even the most committed investigator."

Liberal regulation may contribute to hyperbolic scientific claims and overzealous research agendas, but tight regulatory controls may quash potential therapies or the development of basic scientific information. Regulation has come to represent a degree of safety and reduced liability that facilitates getting a drug to market, rather than setting the research parameters for a novel substance or a novel application. ${ }^{7-9}$ Does this imply that scientists and drug regulators will find themselves at cross-purposes? A 21 st century resurgence of psychedelic research suggests this may be the case.

Evidence is mounting that a new era of psychedelic medicine may be around the corner. Laboratories in the United States and Europe have already been conducting trials for several years. The historical context may have changed to permit these experiments, but who will champion this next phase of psychedelic science? In 1963, Aldous Huxley received LSD on his death bed and suggested that its effects bathed him in a vision of warmth and spiritual belonging, such that he could face death without fear. Palliative care has been an area identified for the potential use of psychedelics for precisely this reason; not as a treatment, but as a psychological therapy that helps people face death. Will the growing need for palliation change the context sufficiently to warrant a second look at
LSD clinically? As baby boomers age, placing greater demands on end-of-life care than we have faced in the past, will they again tip the demographic scales and create sufficient patient demand for LSD?

\section{Erika Dyck PhD}

Department of History, University of Saskatchewan, Saskatoon, Sask.

\section{References}

1. Langlitz N. Neuropsychedelia: the revival of hallucinogen research since the decade of the brain. Berkley. Oakland (CA): University of California Press; 2013.

2. Kupferschmidt K. High hopes. Science 2014;345: 18-23.

3. Oram M. Efficacy and enlightenment: LSD psychotherapy and the drug amendments of 1962 . J Hist Med Allied Sci 2014;69:221-50.

4. Dyck E. Just say know? Criminalizing LSD and the politics of psychedelic expertise, 1961-1968. In: Montigny E, editor. The real dope. Toronto: University of Toronto Press; 2011:169-96.

5. Nutt D1, King LA, Saulsbury W, et al. Development of a rational scale to assess the harm of drugs of potential misuse. Lancet 2007;369:1047-53.

6. Editors. End the ban on psychoactive drug research. Sci Am 2014;310(2):33. Available: www.scientific american.com/article/end-the-ban-on-psychoactive -drug-research/ (accessed 2015 Apr. 2).

7. Marks H. The progress of experiment: science and therapeutic reform in the United States, 19001990. Cambridge (MA): Cambridge University Press; 1997.

8. Healy D. Let them eat Prozac: the unhealthy relationship between the pharmaceutical industry and depression. New York: New York University Press; 2004.

9. DeGrandpre R. The cult of pharmacology: how America became the world's most troubled drug culture. Durham (NC): Duke University Press; 2006.

Funding: This project was funded by a grant from the Social Sciences and Humanities Research Council and a salary award through the Canada Research Chair in the History of Medicine (Tier 2). The funding had no direct impact on the author's research or conclusions.

CMAJ 2015. DOI:10.1503/cmaj.141358

\title{
What happened to you?
}

I reek of salt water: the breath of the Indian Ocean lingers on my tanned skin and sweat trickles down my back, my legs, my nose. A bony elbow juts into my ribs and a stranger's hand rests familiarly on my shoulder while another calloused hand overlaps my own on a sticky, metallic surface: an ordinary train pole suddenly transformed into a quasi-artistic exhibit of palms and digits, a tenuous resting place for desperate hands and reaching fingers, many settling atop one another. To think that a sudden jolt would cause me to lose my balance is absurd; I cannot move. I clutch the pole, an anchor in a sea of bodies, salt water, sweat.

Miraculously, inexplicably, each stop brings more evening commuters. They can't possibly get on. But they do.
Every inhalation is laborious, the breath knocked out of my lungs as people vie for precious space, pushing against my chest, stomping on my feet. I close my eyes, but this only amplifies the impression of making physical contact with a dozen pulsating bodies at once.

Deep breaths. I count each inhalation: One. Two. Three. I count the barely illuminated stops as they go by: One. 
Two. Three. The pattern of letters, once so foreign, are now familiar: Wawasalla, Enderamulla, Horape.

$\infty$

It is the summer of 2014. I am on the Colombo Commuter en route from Colombo, the largest city in Sri Lanka, to Ragama, where a classmate and I are conducting a research project focused on mental health at the Rheumatology and Rehabilitation Hospital. In the month I've been here, I've learned that the train is where I can feel foreign, but also as if I belong; it is where the curious nudge and stare and where the bold interrogate (Where were you born?), but it is also where, at times like this, we are all homogenous - fleshy, tired, en route.

We are animals in a crate, I think to myself. No pretense. No sophistication. Nothing pretty about it. We are nothing but skin and hands and sweat. The times I have felt most aware of my body, of my physical presence, have been instances such as this, tinged with an air of desperation and an obsession with the space I occupy.

It is these chaotic journeys that I later find myself reflecting on in our rented, air-conditioned apartment. Yes, I think of the hospital wards I visit and the local classes I attend, yet the faces that commit themselves to memory with the greatest fidelity are those that I carefully scrutinize through a compilation of furtive glances cast along densely packed aisles.

\section{$\infty$}

Indirectly, I learned the word "vitiligo" on the train. Patchy faces and hands; unexpected, almost shocking spots of white skin. Having never seen depigmentation characteristic of vitiligo before, I went home and googled my observations. Vitiligo. It was a new word added to my medical vocabulary - an easily attained, simple answer. The definition brought me relief.

Not all answers have been so easy.

There was a young man speechmaking in uninterrupted Sinhalese and, at first, I believed him to be a vendor executing a carefully rehearsed script. Hopefully craning my neck over other passengers' heads to peek at his wares, I saw that he was not carrying chilled pineapple slices after all: in the place of imagined snacks

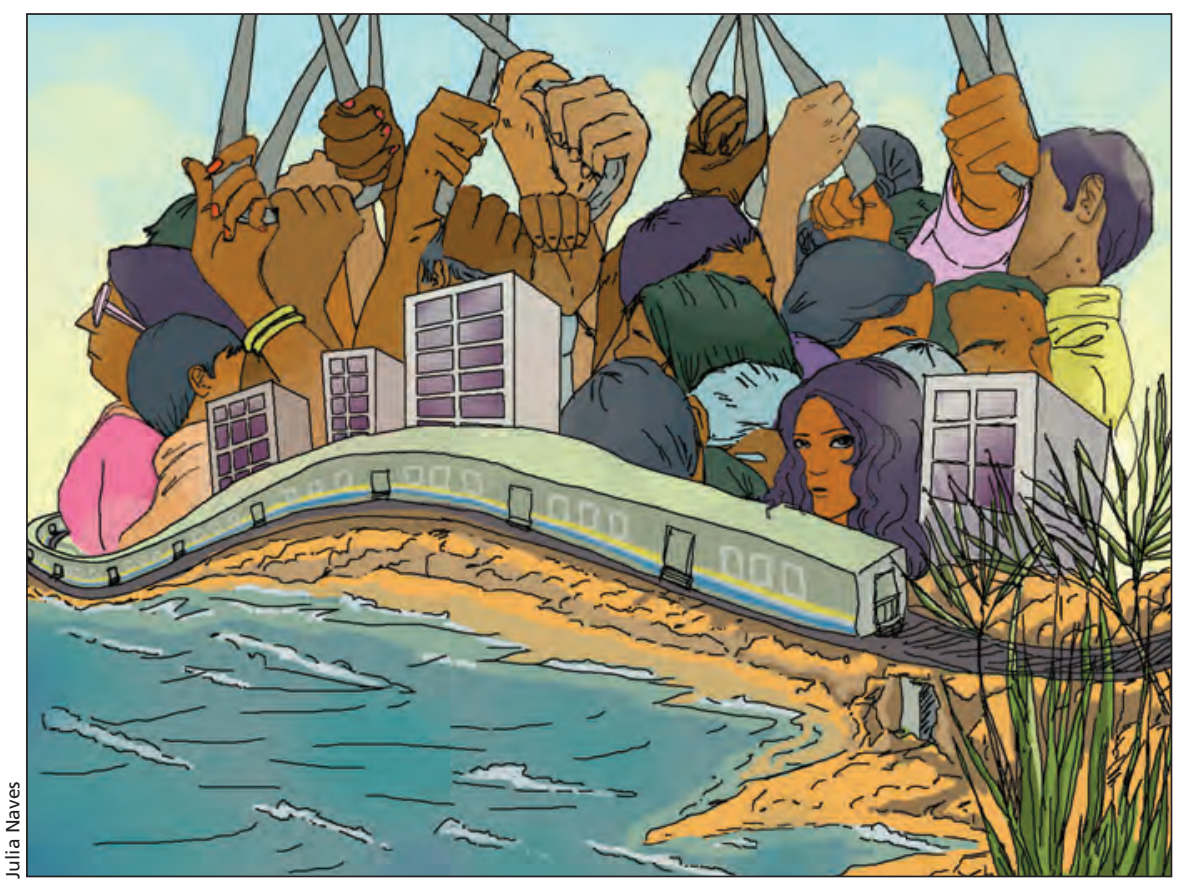

was a flimsy paper, opaque in some areas and completely translucent in others. Perplexed, I stole another glance and was startled: it was an X-ray. He approached my part of the train, jingling a paper cup, presenting his medical image, willing passengers to bear witness to proof of his injury. It was the first time I noticed his limp. What happened to you?

Another trip, another journey, and I felt repulsed by an unexpected, weak grip around my ankle. I looked down to see a one-legged older man, missing a few fingers, dragging himself across the dirty train floor with his functional digits. He slowly waded through feet, his torso reaching other passengers' knees. He was invisible until you heard his low-pitched pleading, felt his unexpected touch on your ankle, heard the familiar jingling cup. My shock gave way to extreme shame at my initial reaction: the cringe at his aged hand clasping my ankle, my withdrawal. What happened to you?

Then there were the scarred faces, unexplained lacerations, stiff movements. Excoriations, scratches, rashes. The lists go on. What happened to you?

$\infty$

During these crammed journeys, I wonder about my fellow passengers; I wonder what ails them, but more than that I wonder about their own journeys. What happened to you? Where are you going? What do you do? I don't understand the language, the subtle gestures, the written signs. I am living in a mystery, surrounded by a thousand individual journeys converging into one, lives thrown unceremoniously into a crowded compartment, paths unknown joining in a strange, physical intimacy. An X-ray of a man's injury, an ancient hand clasping for ankles, a stranger's calloused palm on a shoulder, a dozen sweaty bodies against my skin. In unfamiliar territory, I'm closer to some humans than I have ever been, yet without knowledge of their lives. What happened to you? How do I understand? What can I do?

I wonder, I anguish, I question - at the end of the day, I try and accept.

Accept that, for a while, we have this journey in common - difficult, necessary, shared.

Accept that, for a moment, there we are: bodies sticky with sweat, animal, human, healthy, unhealthy, converging, diverging, hurtling through dark countryside, wading through viscous time.

Temporarily, there we are.

\section{Sumedha Arya BMSc}

Western University,

Faculty of Medicine, University of

Toronto, Toronto, Ont.

CMAJ 2015. DOI:10.1503/cmaj.140941 